\title{
POETRY
}

\section{At sea}

$i$ haunt these hallways by night the engine room churning, coursing under my feet rooms line the hall passengers in matching gowns pumps blinking, torches at the bedside

it is never dark here it never sleeps just s I o w s navigating dark waters each room has life and life can be fickle going overboard, swimming into the night we try to protect and, at times, let it go let it

S

i

n

k

and then

pink sky pours in windows pills in plastic cups

it is morning we can see shore

\section{Alison Dixon MD}

Faculty of Medicine

Dalhousie University

Halifax, NS

CMAJ 2014. DOI:10.1503/cmaj.140275

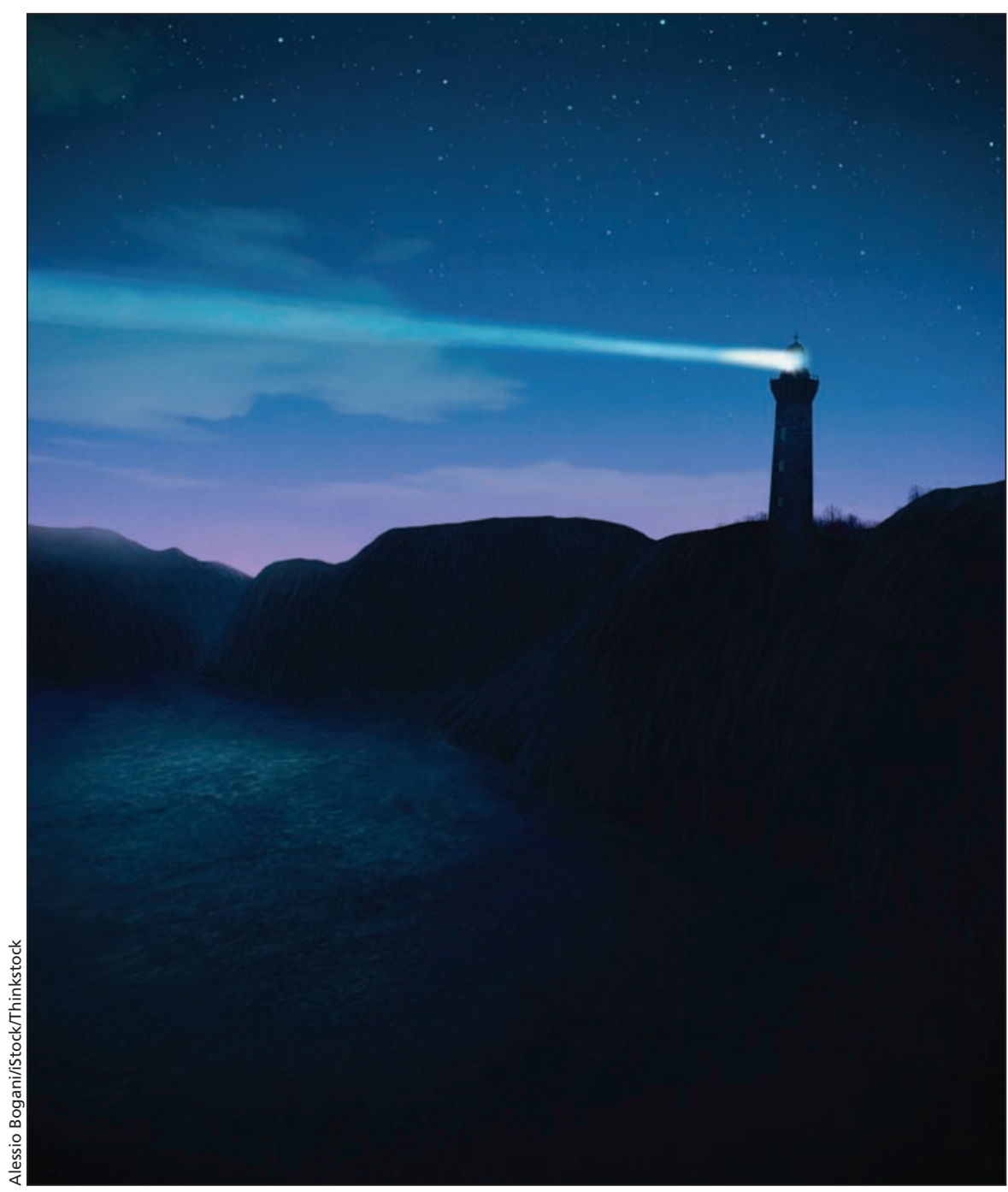

